\title{
Characterization and identification of the most appropriate nonionic surfactant for enhanced oil recovery
}

\author{
Shilpi Sarmah ${ }^{1} \cdot$ Subrata Borgohain Gogoi ${ }^{1} \cdot$ Fan Xianfeng $^{1,2} \cdot$ Annanya A. Baruah ${ }^{1}$
}

Received: 2 November 2018 / Accepted: 6 May 2019 / Published online: 17 May 2019

(c) The Author(s) 2019

\begin{abstract}
The paper focuses on the behaviour of nonionic surfactants (NISs) for enhanced oil recovery (EOR) processes with special reference to its applicability in the reservoirs of Upper Assam. The present work specifically studies three NISs, viz. Tergitol 15-s-7(Tg7), Tergitol 15-s-9 (Tg9) and Triton X 405(TX), based on their surface tension (ST), dynamic interfacial tension, hydrophilic-lipophilic balance, emulsion stability, aqueous stability, particle size analysis and phase behaviour. Simultaneously, crude oil from an oil field of upper Assam Basin was characterized based on API gravity, kinematic and dynamic viscosities, pour point and acid number. Core flood studies were conducted in the reservoir core to determine the recovery of crude oil during secondary water flood and EOR by NISs. It was observed that Tergitol 15-S-7 when mixed with Triton X-405 (Tg7TX) had the least interfacial tension (IFT) as compared to individual NIS and their mixtures. The recovery was found to be as high as $25.67 \%$ after secondary water flood from the original oil in place when Tg7TX followed by chase water was used as an exotic fluid for EOR. This work is an attempt to identify NISs mixtures for EOR for Upper Assam Basin.
\end{abstract}

Keywords Enhanced oil recovery $\cdot$ Nonionic surfactant $\cdot$ Z-average diameter $\cdot$ Nano-sized particle $\cdot$ Phase $\cdot$ Behaviour study · Core flood

\section{Introduction}

Due to the increasing human population, the ever-increasing demand for energy specially hydrocarbon energy cannot be satisfied. The easily extractable volume of crude has already been exhausted, and most of the reservoirs are at their depleting stage of production. Therefore, EOR techniques have been introduced to increase oil production in matured or underperforming reservoirs. At present, the exploration $\&$ production industry is putting a lot of emphasis on the development, optimization and implementation of new EOR methods (Gogoi 2014a, b).

Most matured or underperforming reservoirs of Upper Assam Basin are under chemical EOR (Gogoi 2011, 2014a, b). Already slugs comprising of anionic surfactant/ surfactants/alkali EOR flooding were attempted in most

Subrata Borgohain Gogoi

subrata@dibru.ac.in

1 Department of Petroleum Technology, Dibrugarh University, Dibrugarh, Assam, India

2 Chemical Engineering, The University of Edinburgh, Edinburgh, UK reservoirs of Upper Assam Basin (Phukan et al. 2018; Hazarika and Gogoi 2014). These slugs reduce IFT between the aqueous and oleic phases which in turn increase the capillary number to overcome the capillary forces increasing the microscopic displacement efficiency of the reservoir.

In this study, various NISs were characterized based on ST, IFT, emulsion properties, HLB, particle size analysis and phase behaviour studies. Since the selection of appropriate surfactant also depends on the subsurface fluid properties, characterization of crude oil was done based on API gravity, kinematic \& dynamic viscosities, pour point and acid number. The best-fitted NIS EOR slug was selected based on NIS properties, NIS and reservoir brine interactions and crude oil characterization.

Although anionic surfactants are most widely studied for EOR applications by many authors (Kakoty and Gogoi 2018; Barman et al. 2018; Hazarika et al. 2018; Das and Gogoi 2015), but certain characteristic properties of NIS make it more efficient for instance, its ultra-low IFT, non-volatility and environment friendly surfactant. They have effective solubilization towards water-insoluble or moderately soluble organic compounds and have the capability to alter surface 
characteristics and are stable at high salinity and temperature (Lawson 1978).

\section{Materials and methods}

\section{Material}

Three NISs under study $\operatorname{Tg} 7, \operatorname{Tg} 9$ and $\mathrm{TX}$ were procured from Sigma-Aldrich, Germany. Sodium chloride $(\mathrm{NaCl})$ of $98 \%$ purity was used for the preparation of brine. Distilled water (DW) was obtained from a DW plant. The crude oil sample was collected from an oil field of upper Assam Basin. The other chemicals used were acetone, polyacrylamide (PAM), potassium hydroxide $(\mathrm{KOH})$, phenolphthalein (colour indicator) and ethanol.

\section{Methods}

\section{Characterization of crude oil properties}

Specific gravity (SG) was measured using hydrometer (range 0.9-0.8 SG). API, kinematic viscosity, pour point and acid number were determined by IP standards of $24 / 55$, Cannon-Fenske Routine Viscometer of size 100, standard IP method (15/67) and standard IP method (1/64), respectively (Gogoi et al. 2018).

\section{Characterization of NIS/NISs}

Formulation of the EOR slug The static STs of three NIS (Tg7, Tg9 and TX) were measured in Kruss Easy Dyne S Tensiometer to determine the Critical Micelle Concentration (CMC). The CMCs were obtained for these three NIS at the lowest STs. CMC of $\mathrm{Tg} 7$ was mixed with $\mathrm{Tg} 9, \mathrm{CMC}$ of $\mathrm{Tg} 9$ was mixed with $\mathrm{TX}, \mathrm{CMC}$ of $\mathrm{Tg} 7$ was mixed with $\mathrm{TX}$, and $\mathrm{CMC}$ of $\mathrm{Tg} 7$ was mixed with $\mathrm{Tg} 9$ and $\mathrm{TX}$ as in Table 1. This was done to determine the lowest ST in case of NISs.

The dynamic IFT was determined for $\mathrm{Tg} 7$, TX and Tg7TX as in Table 1 with crude oil as the oleic phase by spinning drop tensiometer of model M6500. This was done to understand the behaviour of NIS/NISs with crude oil

Table 1 Showing the formulation of mixed NISs at CMC values of NIS

\begin{tabular}{lll}
\hline NIS & Formula for mixed NISs & $\begin{array}{l}\text { Mixed } \\
\text { NISs desig- } \\
\text { nated }\end{array}$ \\
\hline $\operatorname{Tg} 7$ & $\operatorname{Tg} 7+\operatorname{Tg} 9$ & $\operatorname{Tg} 7 \mathrm{Tg} 9$ \\
$\operatorname{Tg} 9$ & $\operatorname{Tg} 7+\mathrm{TX}$ & $\operatorname{Tg} 7 \mathrm{TX}$ \\
$\mathrm{TX}$ & $\operatorname{Tg} 9+\mathrm{TX}$ & $\mathrm{Tg} 9 \mathrm{TX}$ \\
& $\operatorname{Tg} 7+\operatorname{Tg} 9+\mathrm{TX}$ & $\mathrm{TTT}$ \\
\hline
\end{tabular}

in terms of IFT reduction ( $\mathrm{Li}$ et al. 2007; Nagaranjan and Wasan 1993).

Determination of HLB of the NIS/NISs The HLB of a NIS is a measure of the degree to which it is hydrophilic or lipophilic. The HLB of the mixture of NISs was calculated as shown below: (Gadhave 2014).

$$
\begin{aligned}
& \text { HLB mixture }=x \text { HLBA }+(1-x) \text { HLBB } \\
& X=x \text { HLBA }+ \text { HLBB }-x \text { HLBB } \\
& X=x(\text { HLBA-HLBB })+\text { HLBB } \\
& X-\text { HLBB }=x(\text { HLBA }- \text { HLBB }) \\
& x=\frac{X-\text { HLBB }}{x(\text { HLBA }- \text { HLBB })}
\end{aligned}
$$

where A \& B are two individual NIS

$x \&(1-x)$ are the HLB fraction of A \& B in the NIS mixtures

$X$ is the HLB value for combined A \& B NIS

HLBA \& HLBB are the HLB values for the individual NIS (A \& B)

Determination of emulsion stability of NIS/NISs The crudeNISs emulsion stabilities were measured using the conventional bottle test method at $27^{\circ} \mathrm{C}$ and $40^{\circ} \mathrm{C}$. Brine salinity of $3500 \mathrm{ppm}$ was prepared and mixed with the seven set of NIS and NISs slugs at their CMC values. Each aqueous solution was mixed thoroughly using magnetic stirrer for $24 \mathrm{~h}$ until a homogenous solution was formed. These solutions were added to crude oil in the ratios of 1:9, 2.5:7.5, 5:5, 7.5:2.5 and 9:1. After addition of crude oil, the mixtures were agitated for approximately $30 \mathrm{~min}$ using a rotameter until a homogeneous solution was formed. The tubes were first allowed to stand undisturbed for $24 \mathrm{~h}$ at ambient temperature. The above process was repeated, the tubes were allowed to stand for $24 \mathrm{~h}$ at $40{ }^{\circ} \mathrm{C}$, and the readings were recorded.

Determination of aqueous stability of NIS/NISs In aqueous stability tests, concentrated stock solutions of NIS/NISs and brine of concentrations 3000, 3500, 4000, 4500, 5000, 5500, $6000 \mathrm{ppm}$ were mixed in a glass vial, agitated and allowed to settle for 1 hour. If the chemicals forming NIS/NISs were unstable in brine at a given salinity and temperature, they will either deposit or separate into distinct dispersed phases. Aqueous stability tests provide an upper value of salinity below which all chemical constituents can coexist in the aqueous phase.

Particle size analysis of Tg7, TX and Tg7TX The particle size analysis of $\mathrm{Tg} 7, \mathrm{TX}$ and $\mathrm{Tg} 7 \mathrm{TX}$ were measured by a laser diffraction method of Zetasizer version 7.11 (Malvern Instruments Ltd.). Size of the droplets was measured based on the best fit between the experimental values and the Mie 
theory (Bera et al. 2012). The software used a dispersant RI of 1.33 during the measurement. All the experiments were conducted at $26^{\circ} \mathrm{C}$.

Phase behaviour study for Tg7TX The phase behaviour studies were conducted following Winsor's Classification of Microemulsion (Liu 2008). The NIS slug for this experiment was Tg7TX selected on the basis of the lowest IFT as obtained in "Formulation of the EOR slug" section. Equal volumes of crude oil $(5 \mathrm{ml})$ and $\mathrm{Tg} 7 \mathrm{TX}(5 \mathrm{ml})$ were taken in tarsons and mixed in rotary mixer for $1 \mathrm{~h}$ at $10 \mathrm{rpm}$. These mixtures were transferred into the sealed pipettes and kept undisturbed at oven temperature of $67{ }^{\circ} \mathrm{C}$ till stable microemulsions were formed.

\section{Core flooding}

Conventional core sample obtained was cut into core plug of 3.5 inches long and 1.5 inches diameter. The plug was cleaned by extracting oil present in the plug by toluene: methanol ratio of 1:1 in a Soxhlet apparatus. Sonication was done in a Digital Ultrasonic Cleaner [Model no. EI500HI] to remove the loose adhering particles on the plug surface and then dried in the dehumidifier till a constant weight is attained. The plug was then coated in Teflon and then inserted into the Hassler core holder of the core flood apparatus. The core flooding experiments were done as in the literature (Gogoi 2014a). Brine flooding was done to saturate the plug and obtain the absolute permeability (K) of the plug. Liquid paraffin oil of API gravity $36^{\circ}$ was used for flooding, as this resemble the API gravity of crude used in this study. There is a limitation of using crude oil in the core flood apparatus as it might block the piping system. Oil flooding was done to obtain the relative permeability of oil w.r.t brine $\left(k_{\mathrm{rw}}\right)$ at initial water saturation $S_{\mathrm{wi}}$. This was followed by secondary brine flooding to obtain the relative permeability of brine w.r.t oil $\left(k_{\mathrm{ro}}\right)$ at residual oil saturation $S_{\text {or }}$. Finally, the $S_{\text {or }}$ was being flooded by the formulated NISs which was Tg7TX until residual oil saturation after Tg7TX $\left(S_{\text {orT }}\right)$ flooding attains a constant value.

The interpretation of this displacement phenomenon occurring in the core flooding apparatus is based on the flow of any homogeneous fluid in a porous solid medium and was

\section{Table 2 Crude oil} characterization attributed to the French engineer Henry Darcy, assuming that all fluids flow in a direction perpendicular to the surfaces of constant pressure and in the direction of pressure decrease (Welge 1952).

\section{Results and discussion}

\section{Characterization of crude oil properties}

The results of characterization of crude oil properties are in Table 2. This was done to select the synthetic oil for core flooding experiments.

\section{Characterization of NIS/NISs}

\section{Formulation of the EOR slug}

The ST of three single NISs samples $\mathrm{Tg} 7, \mathrm{Tg} 9$ and $\mathrm{TX}$ is in Fig. 1 and Table 3. The CMC values of these NISs were mixed as in Table 1, and the STs for four mixed NISs, viz., Tg7Tg9, Tg7TX, Tg9TX and TTT, are shown in Table 4.

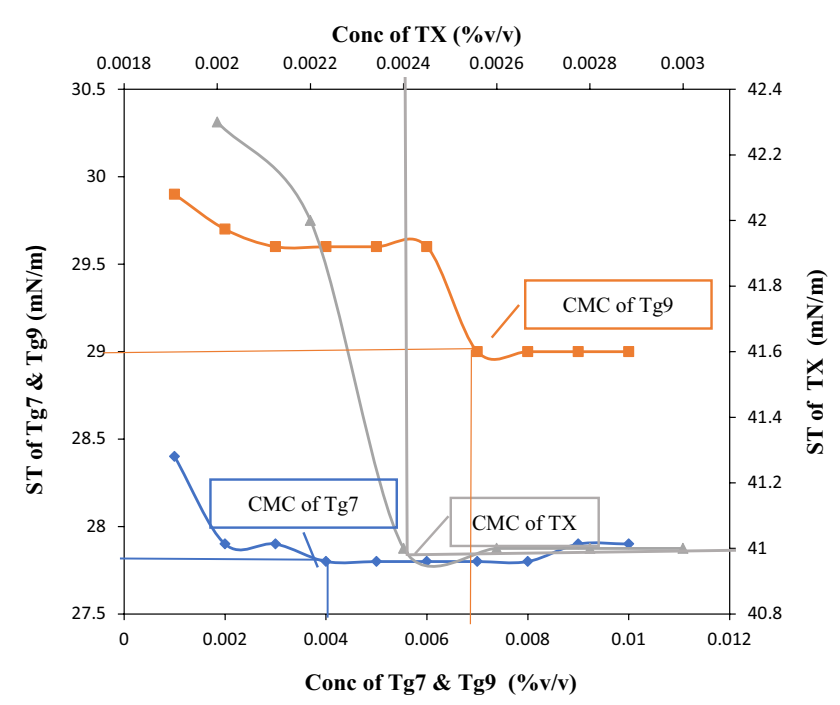

Fig. 1 ST (mN/m) versus CMC (\% v/v) of single NIS

\begin{tabular}{ll}
\hline Parameters & Results \\
\hline SG & 0.844 \\
API $\left({ }^{\circ}\right)$ & 36 \\
Kinematic viscosity at & 10.8 \\
$26{ }^{\circ} \mathrm{C}[\mathrm{cSt}]$ & \\
Pour point $\left({ }^{\circ} \mathrm{C}\right)$ & 18 \\
$\begin{array}{l}\text { Acid number }[(\mathrm{mg} \text { of } \\
\mathrm{KOH}) /(\mathrm{g} \text { of crude }\end{array}$ & 2.01 \\
oil)] & \\
\hline
\end{tabular}

Table 3 ST $(\mathrm{mN} / \mathrm{m})$ versus CMC (\% v/v) of single NIS

\begin{tabular}{|c|c|c|}
\hline NIS & $\mathrm{CMC}(\% \mathrm{v} / \mathrm{v})$ & $\mathrm{ST}(\mathrm{mN} / \mathrm{m})$ \\
\hline Tg7 & 0.004 & 27.8 \\
\hline Tg9 & 0.007 & 29 \\
\hline $\mathrm{TX}$ & 0.0024 & 41 \\
\hline
\end{tabular}


Table 4 ST (mN/m) versus CMC (\% v/v) of mixed NISs

\begin{tabular}{lll}
\hline NISs & CMC $(\% \mathrm{v} / \mathrm{v})$ & IFT $(\mathrm{mN} / \mathrm{m})$ \\
\hline Tg9TX & $0.007+0.0024$ & 29.2 \\
Tg7Tg9 & $0.007+0.004$ & 28.2 \\
Tg7TX & $\mathbf{0 . 0 0 4 + 0 . 0 0 2 4}$ & $\mathbf{2 7 . 5}$ \\
TTT & $0.0024+0.004+0.007$ & 28.7 \\
\hline
\end{tabular}

NIS Non Ionic Surfactants, CMC Critical Micelle Concentration, IFT Interfacial Tension

Table 5 IFT (mN/m) versus CMC (\% v/v) of mixed NIS/NISs

\begin{tabular}{|c|c|c|}
\hline NISs & $\mathrm{CMC}(\% \mathrm{v} / \mathrm{v})$ & IFT $(\mathrm{mN} / \mathrm{m})$ \\
\hline $\operatorname{Tg} 7$ & 0.004 & 2.03 \\
\hline $\mathrm{TX}$ & 0.0024 & 4.61 \\
\hline Tg7TX & $0.004+0.0024$ & 1.57 \\
\hline
\end{tabular}

NIS Non Ionic Surfactants, CMC Critical Micelle Concentration, IFT Interfacial Tension

Table 6 HLB of NIS/NISs

\begin{tabular}{lll}
\hline Chemical & HLB & Interpretation \\
\hline Tg7 & 12.300 & Prone to foaming \\
Tg9 & 13.400 & \\
TX & 17.800 & \\
Tg7TX & 14.287 & \\
Tg9TX & 16.678 & \\
Tg7Tg9 & 12.999 & \\
TTT & 13.820 & \\
\hline
\end{tabular}

Similar studies were also done by (Mandal et al. 2012). The lowest value of ST was observed in Tg7TX as in Table 4.

In Table 5, the IFT results of $\mathrm{Tg} 7$ and $\mathrm{TX}$ and $\mathrm{Tg} 7 \mathrm{TX}$ are shown, wherein the least IFT was observed in Tg7TX indicating the best EOR slug. Besides, the IFTs of Tg7 and TX were also done since these are the individual NIS in the formulation of Tg7TX. Previous studies by (Torrealba and Johns 2018b) showed that the CMC values in the presence of crude oil may vary based on both the surfactant partitioning and also the water-oil ratio.

\section{HLB of the NIS/NISs}

HLB is an important parameter and is specifically calculated for NISs. The NIS depicts broadest range of properties depending upon the ratio of the HLB. Hence, selection of optimal HLB values of NISs for different applications is mandatory according to (Griffin 1954). It is a measure of per cent ethoxylation of the respective surfactant. Table 6 quantifies the affinity of the NIS's for water and oil. Higher the HLB value, more desirable it is for EOR applications. From Table 6, the ethoxylation number can be correlated with HLB. It can be seen that an increase in ethoxylation number (EON) also results in the increase in HLB.

\section{Crude and NIS/NISs emulsion stability}

Crude-NIS/NISs emulsion stabilities were tested to check whether the NIS/NISs were stable when they were in contact with crude oil. This test enables us to determine the most efficient NIS/NISs (Almohsin et al. 2018). The instability of emulsions leads to floating of droplets to the surface, cohesion between droplets and finally separation as discussed in (Salager et al. 2000). The stability of the emulsions depends on the different forces acting on the interface. These include electrostatic repulsive forces and van der Waals attractive forces (Mileva and Radoev 2004). The NIS/NISs were prepared with distilled water and brine of $3500 \mathrm{ppm}$ and agitated for 1 hour. Crude oil and NIS/NISs were then mixed in different proportions to determine which proportion results in stable emulsions. From the experiment in "Determination of Emulsion Stability of NIS/ NISs" section, it was observed that all the NIS/NISs showed the maximum stability at crude oil: NIS/NISs concentration of 9:1 at both $27{ }^{\circ} \mathrm{C}$ and $40{ }^{\circ} \mathrm{C}$ and the least stable was observed at crude oil: NIS/NISs ratio of 1:9 when kept under $48 \mathrm{~h}$ of observation. The results obtained are shown from Table 7.

\section{Determination of aqueous stability of the NIS/NISs}

Aqueous stability tests were carried out to test the stability of chemicals in the electrolyte solution at salinities encountered during corefloods. The NIS's surfactant slug was prepared at 3000, 3500, 4000, 4500, 5000, 5500, $6000 \mathrm{ppm}$ salinity at their CMC concentrations. It was observed that they were stable at all the above brine salinity. There was no separation of phases in the solution. These depict that different range of salinity of the reservoir condition will not affect the stability of the NIS/NISs.

\section{Particle size analysis of Tg7, TX and Tg7TX}

Particle size distributions for $\mathrm{Tg} 7, \mathrm{TX}$ and $\mathrm{Tg} 7 \mathrm{TX}$ in DW and brine are shown in Fig. 2a-f, respectively. The size of $\mathrm{Tg}$ 7, $\mathrm{TX}$ and $\mathrm{Tg}$ 7TX droplets was found to be less than $10 \mathrm{~nm}$ in all the cases. The nanosize of Tg7, TX and Tg7TX slugs is smaller than the pore throats of the reservoir porous media assisting good injectivity and penetration through the smaller pores and increasing microscopic displacement efficiency (Sajjadian et al. 2016). The curves in each case show $\%$ number versus particle size distribution. The $\mathrm{Z}$-average diameter is the mean hydrodynamic diameter and is calculated according to the International Standard on dynamic light scattering ISO13321 (Bera et al. 2012) The Z-average 
Table 7 Table showing the emulsion stability of NIS or NISs

\begin{tabular}{|c|c|c|}
\hline NIS/NISs & $\begin{array}{l}\text { Crude oil: NIS/ } \\
\text { NISs }\end{array}$ & Observations of oil and water phases in the tarson \\
\hline \multirow{5}{*}{$\begin{array}{l}\mathrm{Tg} 7 \text { at } \\
27^{\circ} \mathrm{C}\end{array}$} & $9: 1$ & Thin layer of water at the bottom \\
\hline & $1: 9$ & Separation of phases \\
\hline & $7.5: 2.5$ & Thin layer of water at the bottom \\
\hline & $5: 5$ & \\
\hline & 2.5:7.5 & No separation of phases \\
\hline \multirow{5}{*}{$\begin{array}{l}\mathrm{Tg} 7 \text { at } \\
40{ }^{\circ} \mathrm{C}\end{array}$} & 9:1 & \\
\hline & $1: 9$ & Layer of oil on top \\
\hline & $7.5: 2.5$ & No separation of phases \\
\hline & $5: 5$ & Oil phase on top \\
\hline & $2.5: 7.5$ & \\
\hline \multirow{5}{*}{$\begin{array}{l}\mathrm{Tg} 9 \text { at } \\
27^{\circ} \mathrm{C}\end{array}$} & $9: 1$ & No separation of phases \\
\hline & $1: 9$ & Oil phase on top and a thin layer of oil at the bottom \\
\hline & $7.5: 2.5$ & No separation of phases \\
\hline & $5: 5$ & Bubbles of oil at the bottom \\
\hline & $2.5: 7.5$ & Separate layers of oil \\
\hline \multirow{5}{*}{$\begin{array}{l}\mathrm{Tg} 9 \text { at } \\
40{ }^{\circ} \mathrm{C}\end{array}$} & $9: 1$ & No separation of phases \\
\hline & $1: 9$ & Layer of oil observed on top \\
\hline & $7.5: 2.5$ & No separation of phases \\
\hline & $5: 5$ & Oil layer observed on top \\
\hline & 2.5:7.5 & Oil layer observed on top \\
\hline \multirow{5}{*}{$\begin{array}{l}\mathrm{TX} \text { at } \\
27{ }^{\circ} \mathrm{C}\end{array}$} & $9: 1$ & Very thin layer of water at the bottom \\
\hline & $1: 9$ & Very thin layer of oil formed at the top and bottom \\
\hline & $7.5: 2.5$ & No separation observed \\
\hline & $5: 5$ & Thin layer of water at the bottom \\
\hline & $2.5: 7.5$ & Bubbles of oil and water \\
\hline \multirow{5}{*}{$\begin{array}{l}\mathrm{TX} \text { at } \\
40^{\circ} \mathrm{C}\end{array}$} & 9:1 & No separation of phases \\
\hline & $1: 9$ & Layer of oil on top \\
\hline & $7.5: 2.5$ & \\
\hline & $5: 5$ & \\
\hline & 2.5:7.5 & \\
\hline \multirow[t]{5}{*}{$\operatorname{Tg} 7 \mathrm{TX}$ at $27^{\circ} \mathrm{C}$} & 9:1 & No separation of phases \\
\hline & $1: 9$ & A layer of oil formed at the top and samples of oil stuck to the wall \\
\hline & $7.5: 2.5$ & Thin layer of water at the bottom and a small layer bubbles of air \\
\hline & $5: 5$ & observed above it \\
\hline & 2.5:7.5 & Oil layer on top \\
\hline \multirow{5}{*}{$\begin{array}{l}\mathrm{Tg} 7 \mathrm{TX} \text { at } \\
40^{\circ} \mathrm{C}\end{array}$} & 9:1 & No separation of phases \\
\hline & $1: 9$ & Oil layer separation observed on top of the sample \\
\hline & $7.5: 2.5$ & \\
\hline & $5: 5$ & \\
\hline & 2.5:7.5 & \\
\hline
\end{tabular}

NIS Non Ionic Surfactants

diameter is intensity weighted and is therefore sensitive to the presence of large particles. The results of the particle size analysis of the $\mathrm{Tg} 7, \mathrm{TX}$ and $\mathrm{Tg} 7 \mathrm{TX}$ are shown in Table 8. The relation between Tg7, TX and Tg7TX HLB and Z-average diameter of the particle is shown in Fig. 3. From Fig. 3, it can be understood that with increase in HLB, there is a significant decrease in Z-average diameter thereby increasing $\mathrm{Tg} 7, \mathrm{TX}$ and $\mathrm{Tg} 7 \mathrm{TX}$ activity and efficiency (Mandal and
Bera 2012; Mandal et al. 2012). Again, peak size diameter is also correlated with the dynamic IFT of Tg7, TX and Tg7TX as shown in Fig. 4 (Torrealba and Johns 2017). Z-average diameter corresponds to the mean, with the square root of the polydispersity index (PDI) corresponding to the relative standard deviation of that distribution. However, obtaining a Z-average and PDI does not mean that the distribution is normal distribution, also known as Gaussian distribution as 

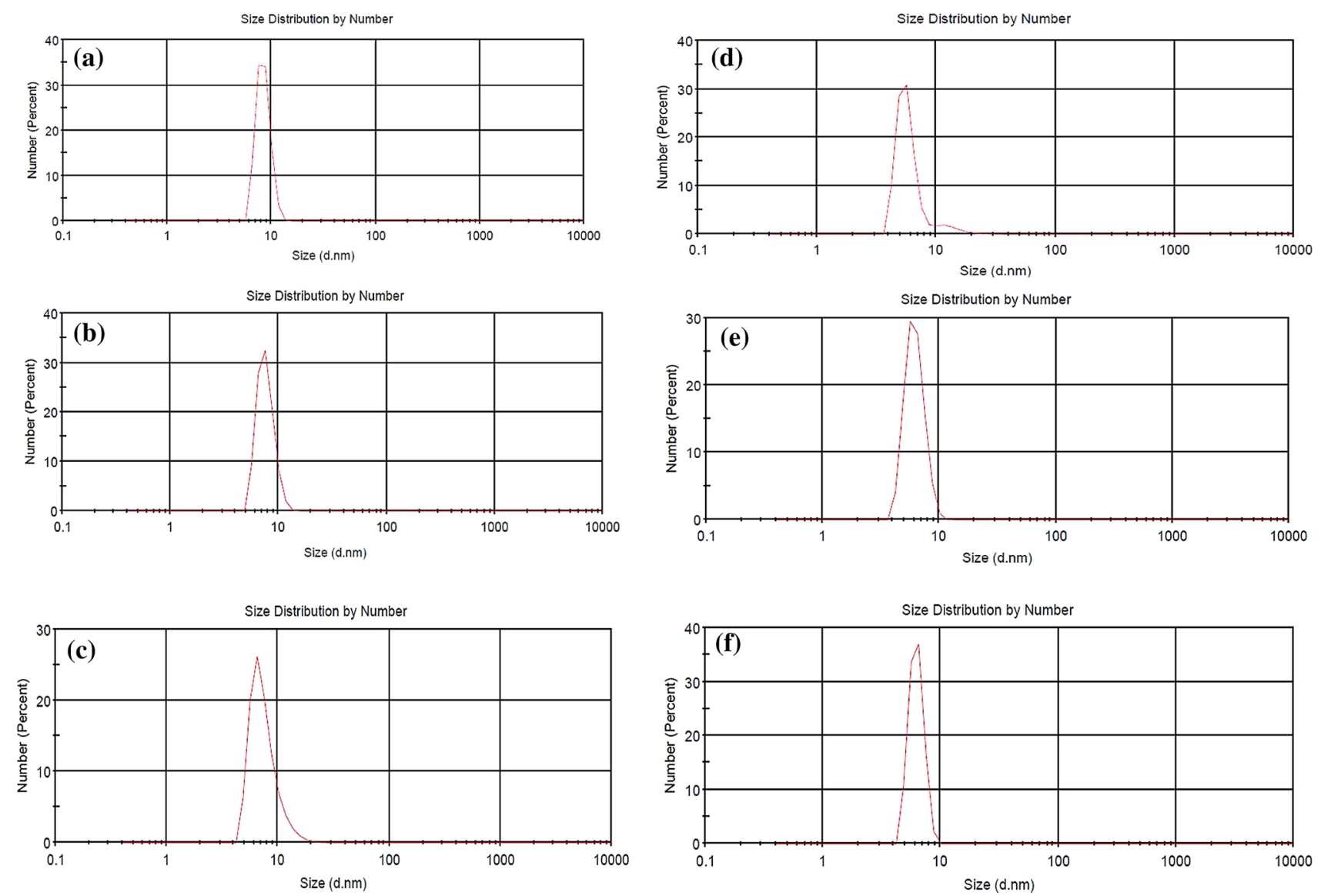

Fig. 2 a Particle size distribution of Tergitol 15-S-7+TX-405 in DW. b Particle size distribution of Tergitol 15-S-7+TX-405 in 2000 ppm brine. c Particle size distribution of Tergitol 15-S-7 in DW. d Particle

size distribution of Tergitol 15-S-7 in 2000 ppm brine. e Particle size distribution of TX-405 in DW. f Particle size distribution of TX-405 in $2000 \mathrm{ppm}$ brine

Table 8 Particle size analysis of $\mathrm{Tg} 7, \mathrm{TX}$ and $\mathrm{Tg} 7 \mathrm{TX}$

\begin{tabular}{llllll}
\hline NIS/NISs & Aqueous phase & $\begin{array}{l}\text { Z-average diam- } \\
\text { eter }(\mathrm{nm})\end{array}$ & PDI & Intercept (\%) & $\begin{array}{l}\text { Peak size } \\
\text { diameter } \\
(\mathrm{nm})\end{array}$ \\
\hline Tg7 & DW & 112.2 & 0.501 & 0.878 & 7.474 \\
\multirow{2}{*}{ TX } & Brine & 114.6 & 0.264 & 0.963 & 5.652 \\
& DW & 40.22 & 0.517 & 0.993 & 6.183 \\
Tg7TX & Brine & 46.9 & 0.561 & 0.987 & 6.242 \\
& DW & 90.15 & 0.471 & 0.930 & 8.361 \\
& Brine & 90.63 & 0.291 & 0.986 & 7.611 \\
\hline
\end{tabular}

in Figs. 2a-f, although smaller PDI values are a good indication that a Gaussian might be a reasonable approximation of the real size distribution (https://www.materials-talks.com/ wp-content/uploads/2014/07/FAQ-What-is-z-average.pdf).

The $\mathrm{Z}$-average is maximum for Tg7-DW and minimum in TX-DW. Peak size diameter is maximum in case of Tg7TXDW and minimum in case of Tg7-brine, indicating that better nano-sized particles are in Tg7-brine. With respect to particle size distribution characterization, a parameter used to define the size range of $\mathrm{Tg} 7, \mathrm{TX}$ and $\mathrm{Tg} 7 \mathrm{TX}$ in brine is called the "polydispersity index" (PDI). The term "polydispersity" (or "dispersity" as recommended by IUPAC) is used to describe the degree of non-uniformity of a size distribution of particles (Nobbmann 2014; Bera 2015). Polydispersity index is also known as heterogeneity index, which is a measure of the distribution of molecular mass in a given test sample. This index is dimensionless and scaled such that values smaller than 0.05 are mainly seen with highly 


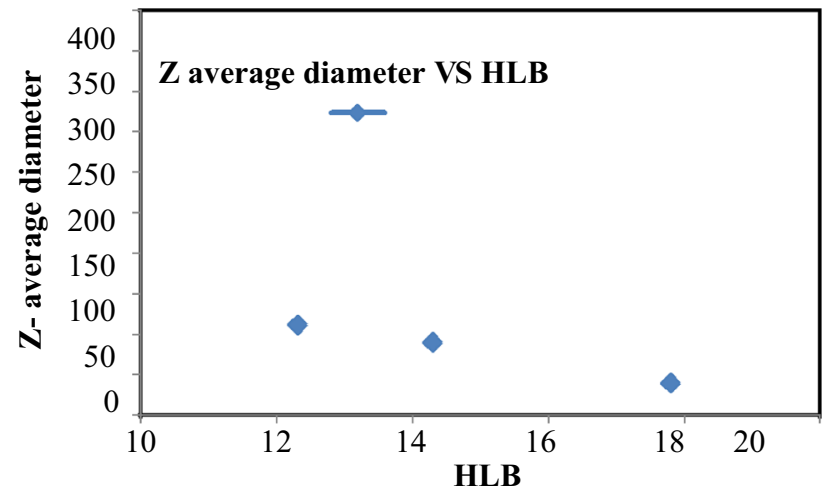

Fig. 3 Relation between Z-average diameters (nm) versus HLB values of NIS

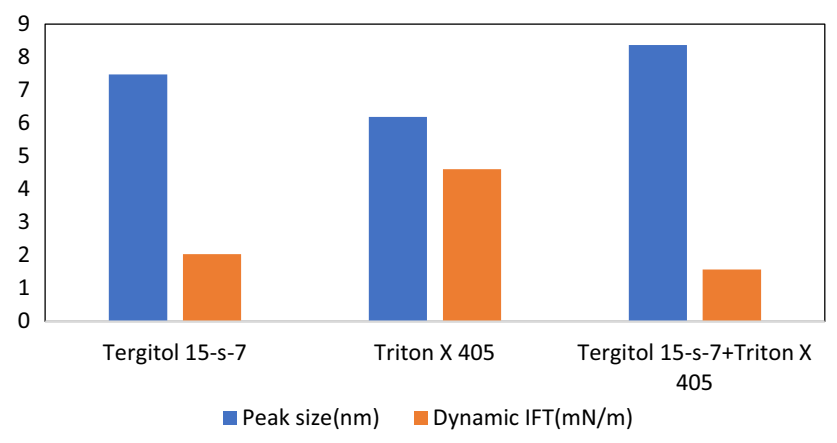

Fig. 4 Comparison of particle size diameter of the NIS/NISs w.r.t dynamic IFT

monodisperse standards. PDI values bigger than 0.7 indicate that the sample has a very broad particle size distribution and is heterogeneous. The calculations used for the determination of size and PDI parameters are defined in the ISO standard documents 13321:1996 E and ISO 22412:2008 (Worldwide 2011). In this case, the particle size analysis of Tg7, TX and Tg7TX is in the range of 0.264-0.561, and the least was for $\operatorname{Tg} 7$ in brine, while the highest was for TXbrine and the average was 0.434 , indicating polydisperse inclined towards heterogeneity as it is closer to 0.7 than to 0.05 .

\section{Phase behaviour study for Tg7TX}

The phase behaviour of microemulsions is important to EOR because it can be used as an indicator of ultra-low IFT. Winsor in 1954 first described the phase behaviour of microemulsions for surfactant, oil and brine system. The phase behaviour of a microemulsion system is a function of types and concentration of surfactants, cosurfactants, oil, brine, alcohol, temperature (Bera et al. 2012). With increase in salinity, the phase behaviour of crude oil NIS/
NISs mixtures changes from Winsor type I to III to II (Torrealba and Johns 2018a, b) . The ideal situation to achieve ultra-low IFT is during Winsor type III formation, and the salinity at which it is formed is called optimal salinity. The salinity where the two tensions are equal is called the optimum salinity, which is one of the most significant quantities in the surfactant EOR. At optimum salinity, the amount of oil and brine solubilized in the surfactant phase is approximately equal (Riswati et al. 2019).

The oil solubilization ratio is the volume of oil present in the microemulsion phase to volume of total active $\mathrm{Tg} 7 \mathrm{TX}$, whereas water solubilization ratio is the volume of water present in a microemulsion to volume of $\mathrm{Tg} 7 \mathrm{TX}$ present in the sample. At optimum solubilization ratio, the oil and water solubilization ratios are equal and corresponding salinity at the optimum solubilization ratio is referred to as optimal salinity. Microemulsion at the optimum salinity is in the middle of the Winsor Type III microemulsion. From Fig. 5, optimum solubilizing ratio or optimum salinity for the $\mathrm{Tg} 7 \mathrm{TX}$ was observed at $4250 \mathrm{ppm}$.

\section{Core flooding}

Core flooding of the NIS's was done to determine their recovery efficiencies. It was completed in four stages, firstly saturating the core with a brine salinity of $2000 \mathrm{ppm}$ to determine the absolute permeability, secondly drainage process where the fully saturated core was flooded with liquid paraffin, followed by 1 st imbibition process where secondary recovery commences and fourthly, 2nd imbibition process where NIS's slug was injected to determine the additional recovery. During the 1 st imbibition process, $S_{\mathrm{wi}}$ and $S_{\mathrm{oi}}$ for the four sets of experiment are shown in Table 9. Approximately $37.30 \%, 38.47 \%, 39.42$ and $42.44 \%$ of oil from the original oil in place [OOIP] were recovered in 1 st imbibition process or water flooding

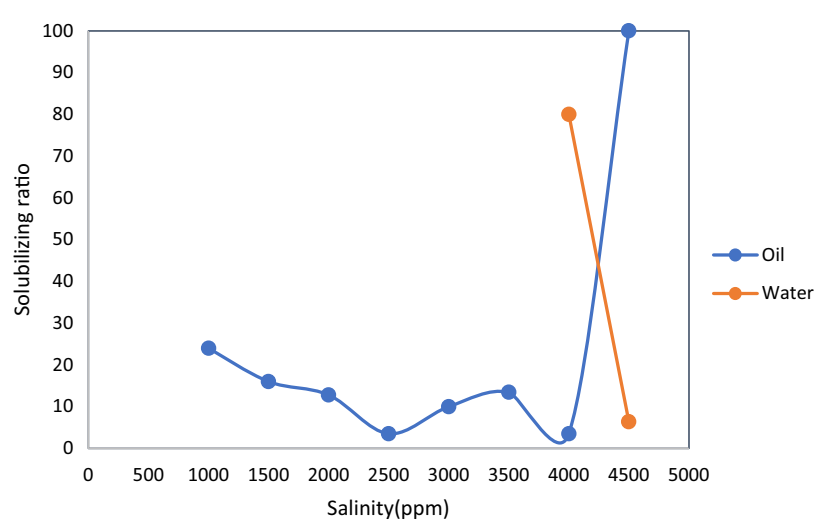

Fig. 5 Solubilizing ratio w.r.t salinity of the NIS slug

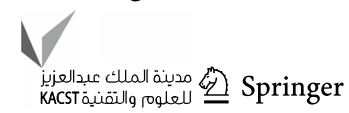


Table 9 Porous media property and oil recovery by nano-sized NIS/NISs

\begin{tabular}{llllllll}
\hline Porosity (\%) & \multicolumn{2}{l}{$\begin{array}{l}\text { Permeability, K } \\
\text { (D) }\end{array}$} & & NIS/NISs flooding & $\begin{array}{l}\text { Additional recov- } \\
\text { ery (\% OOIP) }\end{array}$ & \multicolumn{2}{l}{ \% Saturation } \\
\cline { 2 - 3 } & $K_{\mathrm{w}}$ & $k_{\mathrm{o}}$ & & & $S_{\mathrm{wc}}$ & $S_{\mathrm{oi}}$ \\
\hline 36.467 & 3.4 & 0.021 & $\mathrm{Tg} 7$ & $21 \%$ & 10.67 & 81.56 \\
36.557 & 3.8 & 0.025 & $\mathrm{TX}$ & $23.2 \%$ & 15.12 & 79.68 \\
37.56 & 3.6 & 0.028 & $\mathrm{Tg} 7 \mathrm{TX}$ & $24.0 \%$ & 17.43 & 79.87 \\
37.98 & 3.7 & 0.03 & & $\mathrm{Tg} 7 \mathrm{TX}+$ Chase water & $25.67 \%$ & 18.22 & 80.78 \\
\hline
\end{tabular}

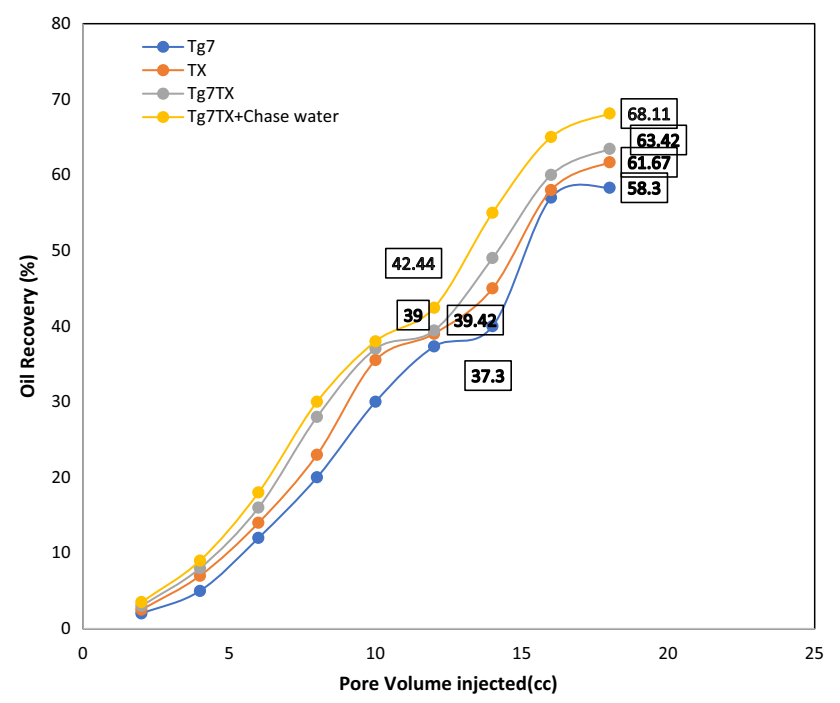

Fig. 6 Oil recovery (\%) w.r.t pore volume injected (cc) for different nano-sized slugs of NIS/NISs

as in Fig. 6. So, a systematic investigation has been done for recovering remaining oil using $\mathrm{Tg} 7, \mathrm{TX}, \mathrm{Tg} 7 \mathrm{TX}$ and chase water assisted $\mathrm{Tg} 7 \mathrm{TX}$.

\section{Conclusion}

The research work attempts to identify NISs to be used as an exotic fluid for EOR in upper Assam Basin. From the results obtained, following conclusion can be made:

1. The crude oil was characterized with an attempt to determine the feasibility of the use of NISs for EOR. Accordingly, the crude oil was found to be light, low viscous and of low acidity which supports surfactant EOR.

2. The increase in ethoxylation number increases the CMC concentration of the NIS.

3. Of all the NISs, the mixture of Tg7TX showed the lowest ST \& IFT.

4. NISs were characterized, and the most effective NISs mixture was $\mathrm{Tg} 7 \mathrm{TX}$. The HLB number of Tg7TX also showed emulsification and detergency properties, thus formed stable emulsion. The $\mathrm{Z}$-average diameter of $\mathrm{Tg} 7 \mathrm{TX}$ was also found to be less.

5. Crude-NISs emulsion stability was observed at a ratio of 9:1. The same was also observed at $40{ }^{\circ} \mathrm{C}$.

6. Proper synergy between the NIS/NISs was observed owing to their aqueous stability and crude oil emulsion stability.

7. NISs droplet size was found to be less than $10 \mathrm{~nm}$, thus assisting mobilization of oil in pore throats and consequently increasing recovery efficiency.

8. The phase behaviour experiments of the selected NISs, Tg7TX, the optimal salinity was observed at $4250 \mathrm{ppm}$, and the Winsor type III was observed at this particular brine concentration.

9. From the core flood experiment, the amount of residual oil that can be recovered by the NIS's was calculated and found to be $21 \%, 23.2 \%, 24 \%, 25.67 \%$ of OOIP for the NIS's of Tg7, TX, Tg7TX and Tg7TX followed by chase water. The latter results in the maximum recovery efficiency that improves both microscopic and sweep efficiencies.

Open Access This article is distributed under the terms of the Creative Commons Attribution 4.0 International License (http://creativeco mmons.org/licenses/by/4.0/), which permits unrestricted use, distribution, and reproduction in any medium, provided you give appropriate credit to the original author(s) and the source, provide a link to the Creative Commons license, and indicate if changes were made.

\section{References}

Almohsin AM, Alabdulmohsen Z, Bai B (2018) Experimental study of crude oil emulsion stability by surfactants and nanoparticles. In: Missouri University of Science and Technology. SPE EOR conference at Oil and Gas West Asia, Muscat, Oman. https://doi. org/10.2118/190440-MS

Barman J, Gogoi SB,Viswanathan J, Konwar D (2018) Formulation of chemical slug for EOR application of moran oil field of upper Assam Basin. In: Sustainability issues in environmental geotechnics, Springer Nature, proceedings of the 2nd GeoMEast: international congress and exhibition, pp 137-150. https://link.sprin ger.com/chapter/10.1007/978-3-030-01929-7_10 
Bera A (2015) Nanoporous silicon prepared by vapour phase strain etch and sacrificial technique. In Proceedings of the international conference on microelectronic circuit and system (Micro), Kolkata, India. pp 42-45. https://pdfs.semanticscholar.org/90d7/5357f aa004f0cf15abf2ad458f8e1253f15d.pdf

Bera A, Kumar S, Mandal A (2012) Temperature-dependent phase behavior, particle size and conductivity of middle-phase microemulsions stabilized by ethoxylated nonionic surfactants. J Chem Eng Data 57(12):3617-3623. https://doi.org/10.1021/je300845q

Das BM, Gogoi SB (2015) Relating IFT with Oil recovery with special reference to bhogpara porous media of upper Assam Basin. J Pet Eng Technol 5(1):1-8

Gadhave A (2014) Determination of hydrophilic-lipophilic balance value. Int J Sci Res (IJSR) 3(4):573-574

Gogoi SB (2011) Adsorption-desorption of surfactant for enhanced oil recovery. Transp Porous Media 90(2):589-604. https://doi. org/10.1007/s11242-011-9805-y

Gogoi SB (2014a) Effluent as surfactant for enhanced oil recovery. Innovative energy policies. J Innov Energy Policies 3(1):40-50. https://doi.org/10.4172/2090-5009.1000109

Gogoi SB (2014b) Petroleum technology-enhanced oil recovery techniques. Oxford \& IBH, New Delhi, pp 45-64. ISBN 978-81-204-1778-6

Gogoi TJ, Gogoi SB, Sarmah S (2018) A Green Approach for Oil Field Produced waters of upper Assam Basin. In: Sustainability issues in environmental geotechnics, Springer Nature, Proceedings of the 2nd GeoMEast: international congress and exhibition, pp 151-171. https://doi.org/10.1007/978-3-030-01929-7

Griffin WC (1954) Calculation of HLB values of non-ionic surfactants. J Soc Cosmet Chem 5:249-256

Hazarika K, Gogoi SB (2014) Comparative study of an enhanced oil recovery process with various chemicals for Naharkatiya oil field. Int J Appl Sci Biotechnol 2(4):432-436. https://doi.org/10.3126/ ijasbt.v2i4.11047

Hazarika K, Yadav R, Gogoi SB, Bhui U (2018) Characterization of crude oil for enhanced oil recovery: a study with anionic surfactant. Int J Ambient Energy 39(2):1-12. https://doi. org/10.1080/01430750.2017.1421573

https://www.materials-talks.com/wp-content/uploads/2014/07/FAQWhat-is-z-average.pdf

http://www.biophysics.bioc.cam.ac.uk/wp-content/uploads/2011/02/ DLS_Terms_defined_Malvern.pdf

Kakoty M, Gogoi SB (2018) Evaluation of surfactant formulation for EOR in some depleted oil fields of upper Assam. In: Sustainability issues in environmental geotechnics, Springer Nature, proceedings of the 2nd GeoMEast: international congress and exhibition, pp 57-75. https://link.springer.com/chapter/10.1007/978-3-03001929-7_5

Lawson JB (1978) The adsorption of non-ionic and anionic surfactants on sandstone and carbonate. In: SPE symposium on improved methods of oil recovery. SPE Journal. https://doi. org/10.2118/7052-MS

Li G, Prasad S, Dhinojwala A (2007) Dynamic interfacial tension at the oil/surfactant-water interface. Langmuir 23(20):9929-9932. https://doi.org/10.1021/la7014463

Liu S (2008) Alkaline surfactant polymer enhanced oil recovery process. Diss., Rice University. https://hdl.handle.net/1911/22224. Accessed Jan 2008

Mandal A, Bera A (2012) Surfactant stabilized nanoemulsion: characterization and application in enhanced oil recovery. In: World academy of science, engineering and technology, vol 6, pp 7. https://waset.org/publications/10032/surfactant-stabilized-nanoe mulsion-characterization-and-application-in-enhanced-oil-recov ery. Accessed 25 July 2012

Mandal A, Bera A, Ojha K and Kumar T (2012) Characterization of surfactant stabilized Nanoemulsion and its use in EOR. In: SPE international oilfield nanotechnology conference held in Noordwijk, The Netherlands. https://doi.org/10.2118/155406-MS

Mileva E, Radoev B (2004) Emulsions: structure stability and Interactions. In: Interface science and technology, Elsevier, vol 4, pp 215-258 https://www.elsevier.com/books/emulsions-structurestability-and-interactions/petsev/978-0-12-088499-5. Accessed 14 Oct 2004

Nagaranjan R, Wasan DT (1993) Measurement of dynamic interfacial tension by an expanding drop tensiometer. J Colloid Interface Sci 159(1):164-173. https://doi.org/10.1006/jcis.1993.1308

Nobbmann UL (2014) Polydispersity-what does it mean for DLS and chromatography. http://www.materials-talks.com/ blog/2014/10/23/polydispersity-what-does-it-mean-for-dls-andchromatography. Accessed 10 July 2014

Phukan R, Gogoi SB, Tiwari P (2018) Alkaline-surfactant-alternatedgas/CO2 flooding: effects of key parameters. J Pet Sci Eng 173(2019):547-557. https://doi.org/10.1016/j.petrol.2018.10.043

Riswati Shabrina S, Bae Wisup, Park Changhyun, Permadi Asep K, Efriza Ivan, Min Byungun (2019) Experimental analysis to design optimum phase type and salinity gradient of alkaline surfactant polymer flooding at low saline reservoir. J Pet Sci Eng 173:10051019. https://doi.org/10.1016/j.petrol.2018.09.087

Sajjadian M, Sajjadianand V, Daya AA (2016) experimental investigation of using nano fluid to improve productivity index on enhancing oil recovery. Int J Min Sci (IJMS) 2(2):13-19. https://doi. org/10.20431/2454-9460.0202003

Salager JL, Marquez N, Graciaa A, Lachaise J (2000) Partitioning of ethoxylated octylphenol surfactants in microemulsion-oil-water systems: influence of temperature and relation between partitioning coefficient and physicochemical formulation. Langmuir 16(13):5534-5539. https://doi.org/10.1021/la9905517

Torrealba VA, Johns RT (2017) Coupled interfacial tension and phase behavior model based on micellar curvatures. Langmuir 33(47):13604-13614. https://doi.org/10.1021/acs.langmuir.7b033 72

Torrealba VA, Johns RT (2018a) Microemulsion phase-behavior equation-of-state model using empirical trends in chemical potentials. SPE J 23(03):819-830. https://doi.org/10.2118/184555-PA

Torrealba VA, Johns RT (2018b) Partition-coefficient relations for improved equation-of-state description of microemulsion-phase behavior. SPE J. https://doi.org/10.2118/179845-PA

Welge Henry J (1952) A simplified method for computing oil recovery by gas or water drive. J Pet Technol SPE. https://doi. org/10.2118/124-G

Worldwide MI (2011) Dynamic light scattering common terms defined; inform white paper. Malvern Instruments Limited, Malvern, pp $1-6$

Publisher's Note Springer Nature remains neutral with regard to jurisdictional claims in published maps and institutional affiliations. 